\title{
Opinion Mining for User Generated Design by Social Networking Service and Japanese Manga
}

\author{
Anak Agung Gede Dharma ${ }^{1}$, Hiroyuki Kumamoto ${ }^{1}$, Shogo Kochi ${ }^{1}$, Natsuki Kudo ${ }^{1}$, \\ Guowei Wei ${ }^{1}$, Shu-Chuan Chiu ${ }^{1} \&$ Kiyoshi Tomimatsu ${ }^{2}$ \\ ${ }^{1}$ Graduate School of Design, Kyushu University, \\ 4-9-1, Shiobaru, Minamiku, Fukuoka, Japan \\ ${ }^{2}$ Faculty of Design, Kyushu University, \\ 4-9-1, Shiobaru, Minamiku, Fukuoka, Japan \\ Email: dharma@kyudai.jp
}

\begin{abstract}
The growth of Social Networking Service (SNS) has created a new potential in marketing. While users communicate and interact via SNS, the list of their conversation, which is called casual data can be used to determine their needs or aspirations. SNS can be very useful for product/service developers, especially when developing new ideas or simply evaluating the feasibility of their existing products/services. Furthermore, SNS provides a unique system that enables expressive and two-way communication between its users. SNS is known for its effectiveness in delivering fresh news and information, thus it can be used as promotional media. Although several online services that utilize SNS and casual data have been provided, the purpose of those services is still unclear and ineffective. In those services, users were only asked for their opinions without receiving sufficient feedbacks. Therefore, to solve these problems we propose an innovative way of utilizing SNS and casual data in designing user generated design. In our proposed system, users can directly contribute to the product/service development process in an interesting way. We designed an online service, which allows users to posts manga that describes their original idea. While contributing to the product/service development, they can also benefit from expressing their hobbies and receiving feedbacks from other users.
\end{abstract}

Keywords: crowdsourcing; Japanese manga; social media; syntax analysis; user generated design.

\section{Introduction}

Social Networking Service (SNS) is widely known as the latest phenomenon in the web communities. Nowadays, web users are able to communicate in a whole different way, which is never happened before. Compared to other online services, SNS allows its users to have two-way communication, utilizing various media, receive feedbacks, organizing social events, etc. In other words, SNS has the possibility to be used for various purposes that involves multiple users altogether with tremendous effect.

Received November $11^{\text {th }}, 2011$.

Copyright (C 2011 Published by LPPM ITB, ISSN: 1978-3086, DOI: 10.5614/itbj.ict.2011.5.3.5. 
In regards of those SNS capabilities and potential, in this paper we propose a new online service, which is designed to serve two main purposes. The first one is to provide a new interesting way to communicate that utilizes SNS and Japanese comic (manga). Furthermore, the second purpose of this system is to provide an interactive promotional media as well as collaborative product/service development tool called user generated design.

To realize those objectives, we developed two main features in our proposed system. The first part is called opinion mining part whose main function is to collect user opinion's data. In this part, users are contributing their ideas in the product/service development without realizing it. The second part, which is called manga part is designed to provide visual feedbacks to the user. User's ideas are visualized in manga that can be rated. Furthermore, user also has an option to post the manga to twitter to expand and express their aspiration.

\section{Background}

As described in our previous works [1], user generated design is a widely used method in designing new products or services. In this method, consumers and producer are involved in the cycle of product design and development, where inputs and feedbacks are shared together. Although this method is highly efficient and cost-effective, it requires an elaborate system design. A common difficulty that is found during its implementation is the lack of understanding of consumer's aspiration. Even when the system is successfully implemented, the final product or service design still does not meet inherent consumer needs.

Recently, the trend of product and service design is changing rapidly due to the influence of SNS. SNS has a role to affect the success of a developing products or services. Recently, web users are getting accustomed to interacting with their friends via internet. In addition, SNS has become more diverse; for example, users are able to publish latest news or information about themselves to others in the same network through different media. As a new product or service starts its development cycle, its popularity and rating can be observed by the quality or quantity of posts within SNS. A good product/service usually received positive feedbacks within the posts and vice versa.

SNS can positively contribute to the success of a product or service. The success of a new product or service development is mainly affected by 2 main factors, i.e.: producer accuracy of predicting consumer aspirations and how well the information regarding the socialization of the new products/services is 
distributed. With the right online service design, SNS can be applied successfully to retrieve users' opinion and give feedbacks to the users.

As for the Japanese culture, Twitter is one of the most commonly used SNS [2]. Along with the increase of communication media, the utilization of Twitter is growing exponentially. There is a tendency to post latest messages, information, or simply emotional expression to Twitter. In regard to the product development, these data are also known as casual data and the method to deal with these data is called abductive thinking [3],[4]. In the strategic product development perspective, we consider this phenomenon as a new opportunity.

Howe [5] proposed a new term called "crowdsourcing" in 2006. Crowdsourcing is a web-based business model that utilizes the creative solutions offered by distributed networks [5],[6]. Brabham [6] describes this concept as follows: "a company posts a problem online and a vast number of individuals responded by offering possible solutions for that problem. Furthermore, he mentioned that by aggregating millions of disparate independent ideas through the technology of the web, crowdsourcing is capable of reducing the costs and time needed to solve the problems [6]".

\section{Related Works}

In this section, we will discuss some works that related to our proposed system. The idea and the principles of using twitter as the interaction medium is based on the interactive work by Chiang et al. who designed an application for Personal Digital Assistant (PDA) that display twitter messages interactively when faced to an AR marker [7].

In addition, we have reviewed relevant network services and considered their significance when designing our proposed system. For example, Cuusoo Seikatsu and Mystarbucks Idea were provided by business owners. Their service utilizes SNS and focuses on gathering consumer ideas and determining voice of the customer, especially their preferences and expectations of a certain product or service.

Furthermore, shindanmaker is a popular network service in Japan that enables its users to create and customize input based diagnosis. When their self-made diagnosis is published, other users can participate by filling their username into a form and have a diagnosis based on the username. 


\subsection{Cuusoo Seikatsu}

"A site where everyone's wishes come true" is the catchphrase of this network service [8]. As it implies, Cuusoo Seikatsu provides an online service where ideas can be shared and published. In addition, interesting ideas has the possibility to be realized. Cuusoo Seikatsu services are directed for manufacturers. Manufacturer can create an account on cuusoo seikatsu and have a dedicated web domain. They can issue their own policy in that domain and customize the contents.

To participate in cuusoo seikatsu, users can visit the manufacturer's page. In that page, they can contribute their ideas or rate existing ideas. The ideas can be contributed in the form of drawn sketches or pictures. Furthermore, the manufacturer may produce a certain idea based on its rating.

\subsection{My Starbucks Idea}

Mystarbucks idea provides an internet service where starbucks customers can share and discuss their ideas [9]. Highly rated ideas have the potential to be realized by Starbucks. To participate in this service, user simply needs to describe their idea and publish it. User can vote the idea and discuss about it. Good ideas can be known quantitatively by its rating and qualitatively by the comments posted by other users. The ideas can also be shared through SNS, e.g.: Facebook, Twitter, or Myspace.

\subsection{Shindanmaker}

Shindanmaker is a network service that provides a custom-made diagnosis tool for Twitter users [10]. At present, shindanmaker is gaining popularity in young Japanese Twitter users. To use this service, the user has to fill the form with his/her registered twitter account. Shindanmaker engine will analyze the account and suggest a diagnosis result as the output.

In addition, shindanmaker allows its users to create or customize their own diagnosis system easily. User can simply name the diagnosis title and fill the entries (up to five) with the desired results. Each entry can contain up to 255 variables and will be displayed randomly depending on the input.

\section{System Design}

SNS utilization in designing a network service to describe the overview of our proposed concept has been discussed in previous sections. In this section, we will describe the mechanisms of our proposed idea in details, system architecture regarding database and networking, features, and the benefits of the 
system. We designed an online service that enables two-way communication between product/service developer and consumer. Product/service developer can use this service for publishing their idea while receiving inputs from its consumer. On the other hand, consumer can directly contribute to the cycle of product development by expressing and sharing their idea.

We proposed to use manga as the method to express the idea. Instead of actual representation or image of the product, manga has several key advantages such as: (1) Compared to the sketch that merely provides simple visualization, manga provides a storyline that describe the narrative of idea, possible applications, or limitations; (2) As we found that many Japanese young people draw manga as their hobby, this service can be a suitable media to express their hobby while receiving feedback from general public; (3) As the online content, manga can be enjoyed by various web users.

\subsection{User Generated Design Mechanism}

User generated design is a design method where a product is designed as a result of consumer voice and aspiration. In this research, we propose an online system where the producer publishes a question regarding product development and users can openly contribute by suggesting opinions or sketches (Figure 1). Our proposed system is focused on two scenarios where users can openly contribute: (1) Users plays a role as a respondent, they were asked for their opinions regarding a design concept, these users will receive visual images as the feedback; (2) Users actively contribute their idea by posting manga sketches, which are designed according to a specified theme.

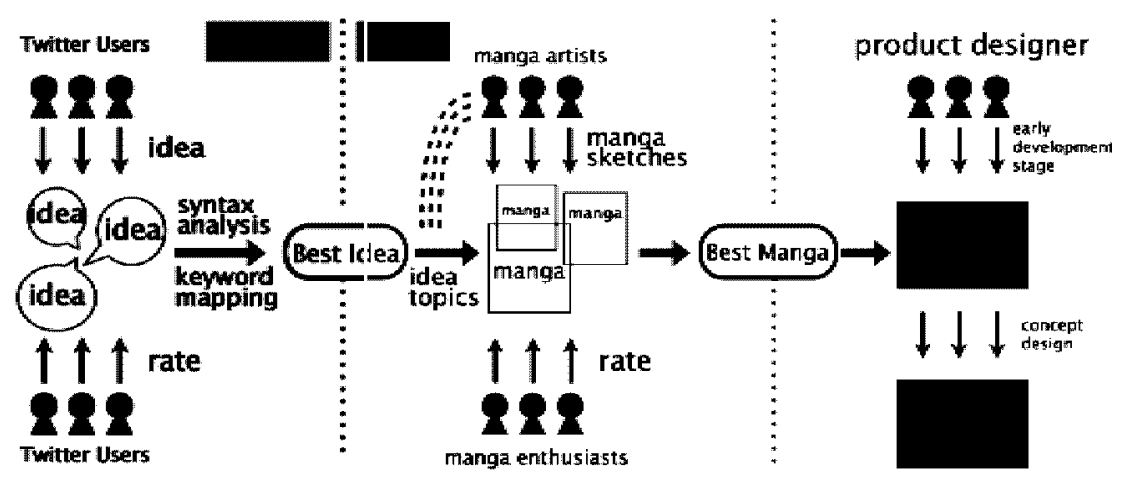

Figure 1 An architecture diagram of our proposed system of integrating SNS and Japanese Manga in Strategic Consumer Generated Design. Ideas from users are collected online and broken down into keywords and syntaxes. These ideas are visualized in the form of manga by manga artists and enthusiasts, which also can be used by product designers to design or develop new products. 


\subsection{System Architecture}

Our system was developed on html5 web environment. In addition, we were also using php and javascript as the web programming language, and mySQL as database. Our system is designed to analyze user's input with syntax analysis, store it into database, and publish it to twitter. In addition to the web programming environment, we also used 2 different Application Programming Interface (API), i.e. Twitter API from Twitter and Syntax Analysis API from Yahoo! Japan [11],[12].

We used Twitter API to publish user's opinion into Twitter while attaching a Uniform Resource Locator (URL) that redirect to our service, in order to make our system known to general public and broaden its scope. We used OAuth Authentication to let the user decide whether they want to publish their opinion into Twitter or not. We believe that this approach will let the user to be in control of their actions while using our system.

Furthermore, to analyze consumer's aspiration in the form of casual data, we used Morphological and Syntax Analysis API, which is provided by Yahoo! Japan. Morphological and syntax analysis are related to the process of breaking sentence down to its components and dependencies.

\subsubsection{Morphological and Syntax Analysis}

We were using morphological and syntax analysis algorithm to break down the sentence input into words, parses, and dependencies. In our system, we used two separate APIs from Yahoo! Japan, i.e. Japanese morphological analysis and Japanese dependency parsing analysis. Japanese morphological analysis handles words extraction from each sentence and defining their parse. Each word dependency is analyzed with Japanese dependency parsing analysis.

In addition, we also used Twitter API at the login page. Twitter API requires web based OAuth process to authenticate the web application. User has to log in using his/her twitter ID to access our system. After log in, user will be asked to input a sentence. The sentence analysis can be classified into 2 parts, i.e. morphological analysis and syntax analysis.

Morphological analysis is the process of breaking the sentence down into morphemes and assigns the suitable lexical class to each morpheme. Yahoo API classifies lexical class into 13 types, i.e.: adjective, quasi-adjective, interjection, adverb, adnominal adjective, conjunction, prefix, suffix, noun, verb, particle, auxiliary verb, and unique lexical classes. 
Syntax analysis is the process of breaking sentence down into its parts of speech with an explanation of the form, function, and syntactical relationship of each part. Japanese dependency pairing analysis can be included as syntax analysis. This analysis adds an additional parameter, i.e. dependency (syntactical relationship) that describes the list of dependent morphemes in a given morpheme.

The final result of morphological and syntax analysis consists of word, parse, and dependency. We repeat these analyses every time new sentence is identified and if any duplicate word is detected it will increase the frequency. Furthermore, rating means the relevancy of a specified word based on consumers' votes. Word, parse, dependency, rating, and frequency are classified as different fields in the database. The illustration of these processes is shown in Figure 2.

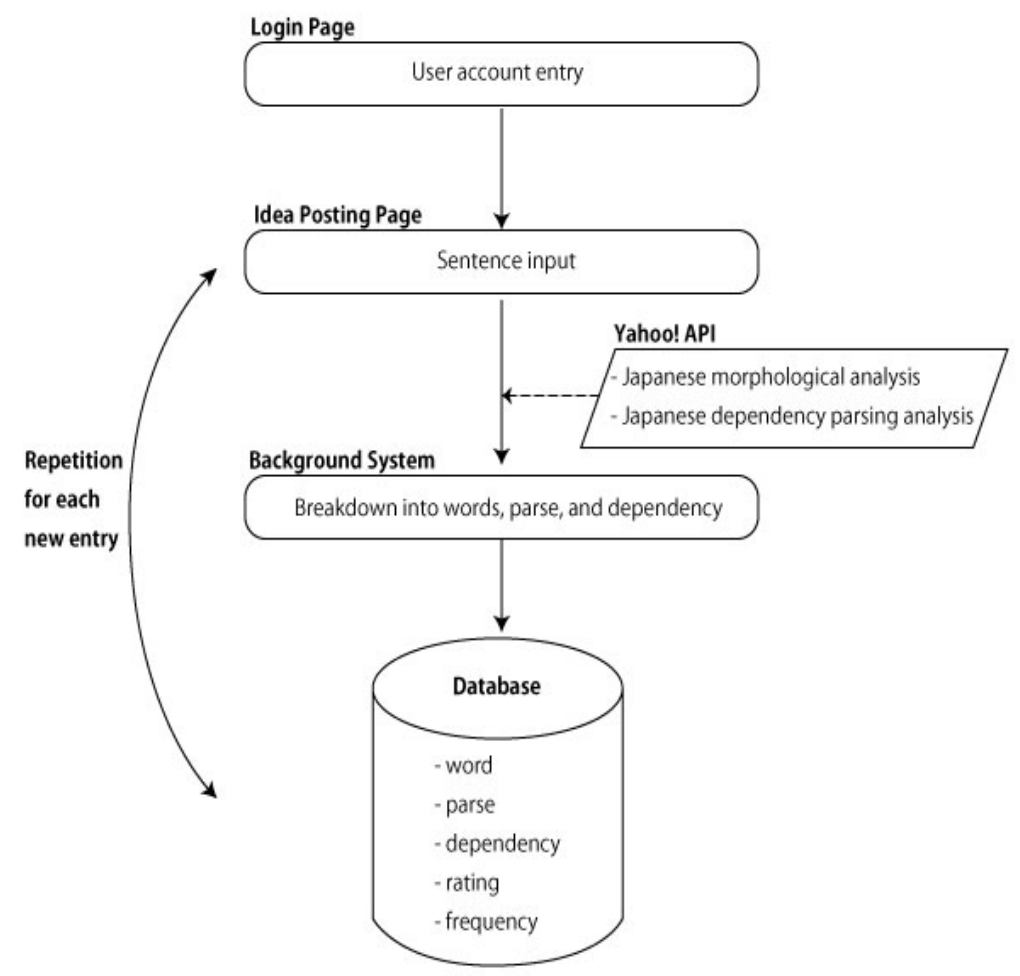

Figure 2 Morphological and Syntax analysis algorithm in our proposed system. 
An example about the sequence of morphological and syntax analysis is described in Figure 3. The analysis begins with morphological analysis. At this point, the sentence “太郎とワインを飲んだ” (i.e. to drank wine with Taro) is broke down into morphemes and suitable lexical classes were assigned. In this example, the sentence is composed by 6 morphemes and has the following sequence: noun, particle, noun, verb, and auxiliary verb. However, the syntactical relationships between morphemes are not analyzed in this step.

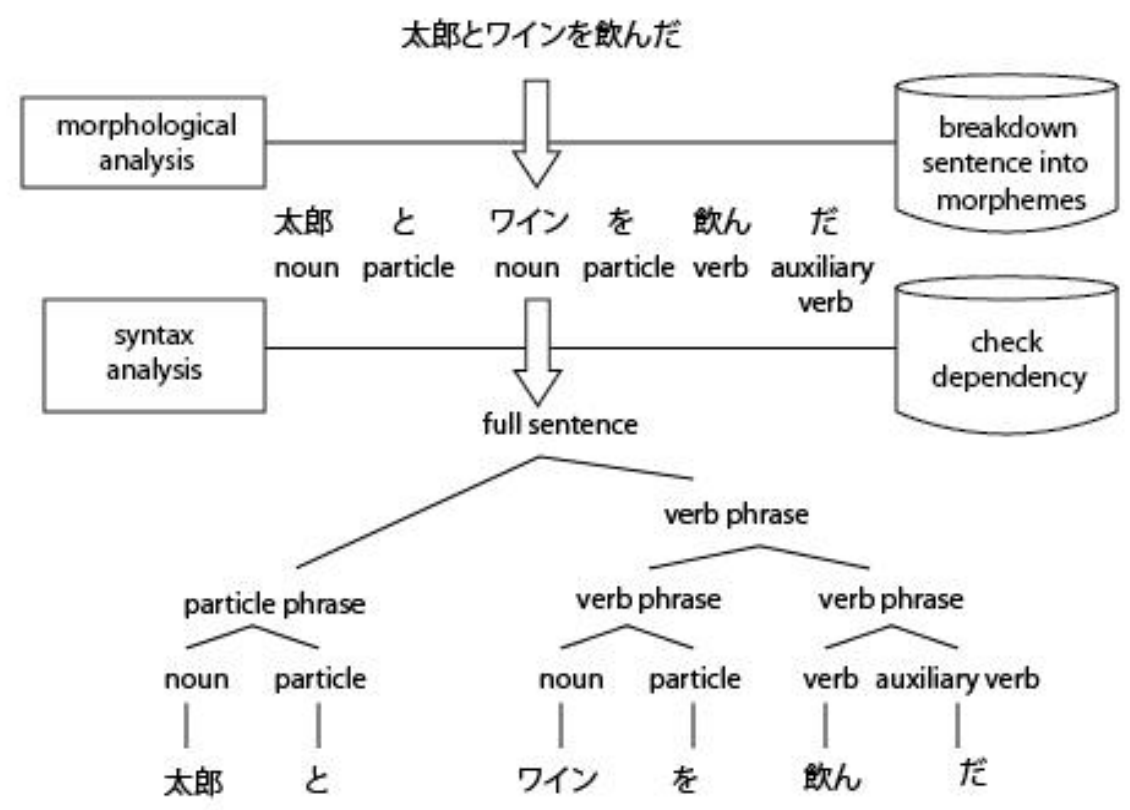

Figure 3 An example of morphological analysis and syntax analysis.

After suitable lexical class is assigned into each morpheme, the following step is to perform syntax analysis.

(1) The analysis of contextual meaning: In Japanese sentences, the contextual meaning of a sentence is determined by particles. In the example, “と” (i.e. Japanese particle used for quoting) marks the end of the first phrase (particle phrase) and start the second one (verb phrase).

(2) Describing syntactical relationships between morphemes:In the example, two morphemes can be described as having a syntactical relationship if they are located within a phrase. For example, the 
morpheme “ワイン (wine) and 飲ん (drink)”,“ワイン and を (i.e. Japanese article that indicates direct object of action)", and “ワイン and だ (i.e. a form of Japanese copula)" are located within a verb phrase and can be defined as syntactically dependent.

(3) The exclusion of redundant data: Another important consideration in the syntax analysis is the exclusion of redundant data. Although 飲ん, を, and だ are dependent to ワイン; を and だ is classified as particle and auxiliary verbs, respectively. Based on redundancy assumption, both of those morphemes are excluded in the database.

(4) Storing relevant data into database:We only consider ワイン and 飲ん to be stored in the database. Thus, in the database, the word ワイン is defined as noun and dependent to the word 飲ん.

\subsubsection{Simulation and Visualization of Morphological and Syntax Analysis}

The principle of morphological and syntax analysis has been described in 4.2.1. In this section, an example of the simulation for the syntax analysis and its visualization will be discussed. After morphological and syntax analysis, sentences are broken down into morphemes and dependencies. A possible result after a series of inputs, syntax analysis, and record are listed in Table 1.

Our proposed system is able to identify the same morpheme with different dependency, i.e.: by assigning a different unique ID to each pair of morpheme and dependency. As described in table 1, for example there are two recorded data for the morpheme “タイヤ (tire)". However, due to each morpheme has different dependency, i.e. “ない (without)” for the first morpheme and ”車 (car)” for the later one, thus they are classified into two different unique IDs (Table 1).

The example of the visualization of syntax analysis result is shown in Figure 4. Each square represents a word in the database and the line between two squares represents their dependency. The size of the square and the thickness of the line are correlated to the word's frequency and dependency, respectively. We referred to Fry [13] in visualizing the result of syntax analysis.

In the visualization graph, we did not include particles as we regard it to be irrelevant. We only consider some lexical classes to be important to be shown in the visualization, i.e.: verb, noun, and adjective. 
Table 1 Four different fields in the database after morphological and syntax analysis.

\begin{tabular}{c|l|l|c}
\hline unique ID & \multicolumn{1}{|c|}{ morpheme } & \multicolumn{1}{c|}{ dependency } & frequency \\
\hline 01 & タイヤ (tire) & ない (without) & 2 \\
02 & ハンドル (handle) & 操作 (to operate) & 3 \\
03 & タイヤ & 車 (car) & 2 \\
04 & 車 & 欲しい (want) & 4 \\
05 & ドライバ (driver) & 居ない (without) & 4 \\
06 & ハンドル & ない & 3 \\
07 & ガソリン (gasoline) & ダメ (useless) & 3 \\
08 & 自動 (automatic) & 車 & 3 \\
09 & 運転 (to drive) & 車 & 2 \\
10 & ガソリン & 不要 (unnecessary) & 2 \\
11 & スタンド (stand) & 不要 & 4 \\
\hline
\end{tabular}
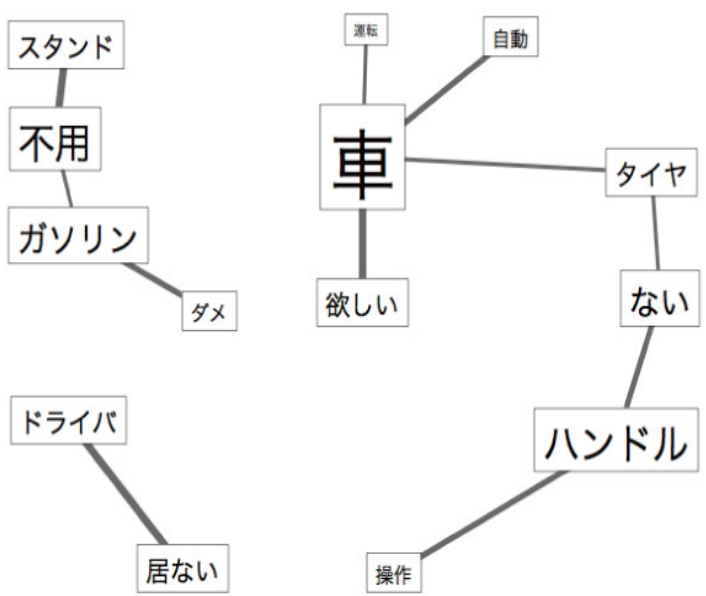

Figure 4 An example of the visualization of syntax analysis result based on the database fields in Table 1.

The visualization of syntax analysis can be a useful tool for product/service developer to summarize the ideas. For example, as shown in the graph (figure 4), the combination of 車, 自動, タイヤ, ない, 欲しい, which respectively means car, automatic, tire, non-existent, and want describes that a part of customers want automatic car that without any wheel, which implies a possible 
technology in the future. We were using this tool in our prototype to create the design themes that will be used by active users to design the manga.

In our proposed online service, thismorphological and syntax analysis is used in the opinion mining part to accumulate and sort users' opinions. The details of its application will be discussed in Section 5.1.

\section{System Features}

As discussed in the previous section, we are targeting two different types of users, i.e. respondents and contributors. In order to accommodate both types of user, we provide two different parts of the system, i.e. opinion mining part and manga part. Opinion mining part is designed for respondents and manga part is designed for contributors. The details of both parts will be discussed in the next sub-sections.

\subsection{Opinion Mining Part}

The first part of our proposed system is called Opinion Mining Part. In this part, the scenario happens in the following sequences:

(1) User opens the login page and insert his/her Twitter's account name (Figure 5-a).

(2) A sketch that illustrates conceptual product is displayed at random. In order to stimulate user ideas, user is required to write their idea in the idea entry form (Figure 5-b).We used a simple algorithm that converts user name (in string) into integer value. The random sketch is selected based on the corresponding integer value. We have a total of 20sketches, thus we calculate the sketch-ID according to equation 1 :

$$
\mathrm{f}(\mathrm{n})=\mathrm{U} \bmod 20
$$

where:

$\mathrm{f}(\mathrm{n})=$ sketch ID

$\mathrm{U}_{\mathrm{n}} \quad=$ Converted string to integer value of a user name

(3) User is given an option to post the idea on Twitter. A URL to the illustration and login page is added automatically in confirmation page. As described in section 4, Twitter API requires web based OAuth process to authenticate the web application. If the user presses the tweet button, a 
pop-up window will appear and ask for confirmation to post the idea to Twitter's timeline.

(4) In the last page, a list of previously posted opinions is given to user. User has the option to rate the opinion by selecting “いい将! (i.e. I like it)" button (Figure 5-c). If an opinion is selected, its rating will be increased by one. When another user sees this page, it always displays the latest rating value of each opinion.

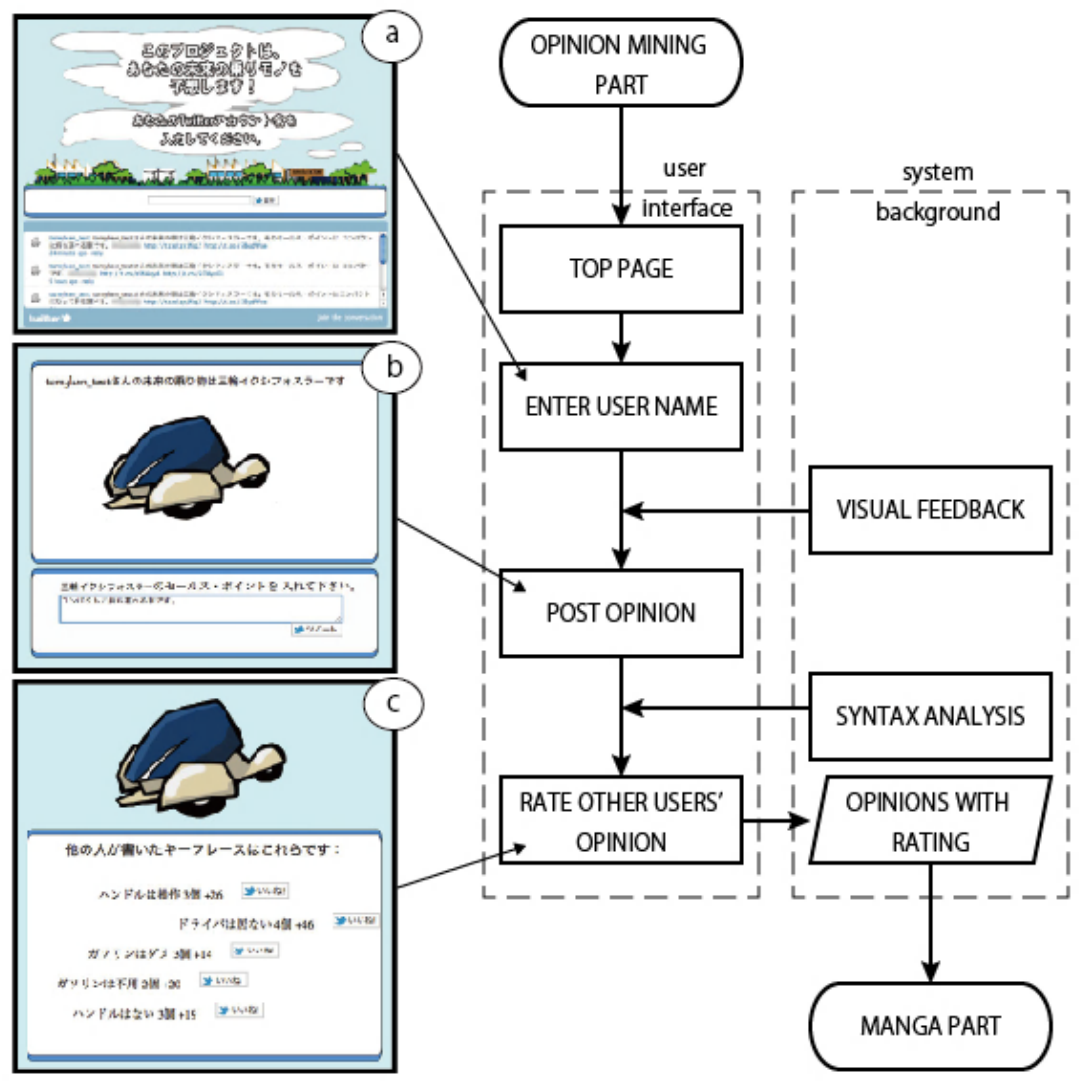

Figure 5 The opinion mining part(a) Login page (b) Idea entry page (c) Rating Page. 


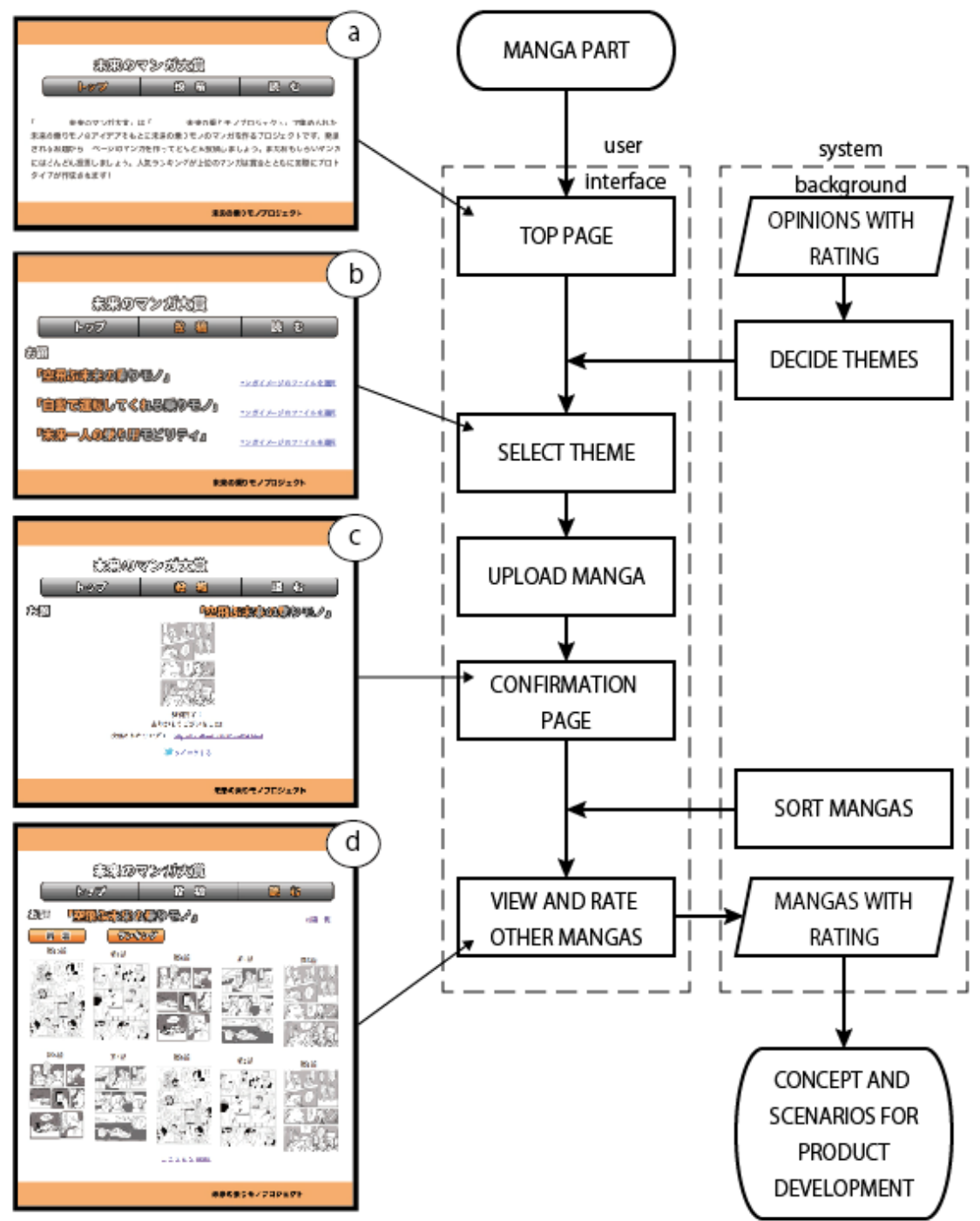

Figure 6 The manga part (a) top page (b) theme selection page (c) upload confirmation page (d) A grid view of mangas. 


\subsection{Manga Part}

In addition to the Idea Collection Part, we also provided Manga Part. In this part, manga enthusiasts can publish their own original works while receiving feedbacks from other users. Manga contributors can publish their manga according to the following steps:

(1) The top page describes outline and general themes so contributors can get an understanding about the system in general (Figure 6-a). Below the title, we provide three tabs for navigating this website, i.e.: トップ, 投稿, and 読む, which respectively meantop, contribute, and read.

(2) When selecting the second tab (投稿), contributor can select a list of available themes and uploads their manga (Figure6-b). After finish uploading, a confirmation page will be loaded, which also includes a thumbnail of their manga (Figure 6-c).

(3) They can view the grid view of the mangas and sorted them based on latest contributions or rank if they select the third tab (読む) as described in Figure6-d.Furthermore, if they select one of the thumbnails, the viewing page will be opened and user can read the selected manga and rate it.

Product/service developer may decide the themes of the manga based on the result of syntax analysis. The themes are updated regularly every significant change in the database occurs, thus making this manga part is essentially integrated with the opinion mining part.

\section{Discussion}

\subsection{Benefits of the Proposed Service}

We consider that our proposed service will be able to provide benefits to both product/service developer and consumer. In this section, we will describe those benefits in details.

\subsubsection{Product/Service Developer's Benefits}

Our proposed service can benefit product/service developers in the following regards:

(1) The developer can have their projects evaluated by their customer during the development stage. Therefore, during its development process, developer can decide whether to utilize more resources for the project or 
postpone it. In particular, the system provide more assistance if the developer has simultaneous ongoing projects.

(2) Casual data can be retrieved and visualized, which also accurately reflects user's aspirations. Furthermore, the producer can decide the designs based on those aspirations and eventually produce them.

\subsubsection{Consumer's Benefits}

In addition, our proposed system could benefits consumers in these following ways:

(1) General consumers can find interesting and enjoyable online contents in the form of manga.

(2) Manga enthusiasts can find others with similar hobby and share their ideas. Furthermore, they can receive quality feedbacks from other users in order to improve their ability in the future. This benefit can be a great consideration to the manga enthusiasts that aspire to be a professional manga illustrator.

\subsection{Benchmarking}

\subsubsection{User Feedbacks}

We had a presentation session with a team of professional product developer to review the feasibility and possible applications of our proposed system. They stated that the system has the potential to be applied as an online service. As described in Section 6.1.1, essential data for product development can be obtained through the system and will benefit product developer. Moreover, by applying an appropriate scenario, users can be encouraged to participate in this system, i.e. either as evaluator or active contributor.

They stated that the idea was very interesting and still has the possibility to be extended further. As we have accomplished the main framework, different media or expression could also be applied in our system. In addition to manga, the system could also utilize animation or game after some minor modifications. As the SNS will continue to progress in the future, our proposed system was the first step to develop online services that facilitate user generated design.

\subsubsection{Comparison with Other Crowdsourcing Service}

For the comparison, we selected 2 online services that fulfill the criteria of crowdsourcing described by Howe [5] and Brabham [6], i.e.: (1) the service harness the solutions of an undefined (and generally large) network of people in 
the form of an open call; (2) it is a web-based business model; and (3) the company takes the design, fabricates it, and sells it.

In regard to these criteria, we select "Lego Cuusoo,"which utilizes crowdsourcing service provided by Cuusoo Seikatsu. Another selected online service for this comparison is "My Starbucks Idea."Furthermore, shindanmaker is not included in this comparison because it does not produce any design in particular thus does not fulfill the crowdsourcing criteria. The summary of the comparison of our proposed system with other crowdsourcing service is described in Table 2.

Table 2 Benchmarking chart of our proposed system with other related methods.

\begin{tabular}{|c|c|c|c|}
\hline & Lego Cuusoo & MyStarbucks Idea & $\begin{array}{c}\text { Our Proposed } \\
\text { Service }\end{array}$ \\
\hline Target users & $\begin{array}{l}\text { Customers with } \\
\text { strong interest in } \\
\text { design }\end{array}$ & General customers & $\begin{array}{l}\text { Young twitter users } \\
\text { with interest in } \\
\text { vehicles }\end{array}$ \\
\hline $\begin{array}{l}\text { Form of } \\
\text { contribution }\end{array}$ & $\begin{array}{l}\text { 1. Sketch or } \\
\text { pictures } \\
\text { 2. Comments } \\
\text { 3. Support / rate }\end{array}$ & Textual ideas & $\begin{array}{l}\text { 1. Textual ideas } \\
\text { 2. Manga } \text { sketches }\end{array}$ \\
\hline UserID & $\begin{array}{l}\text { Independent } \\
\text { user's ID }\end{array}$ & Independent user's ID & Twitter username \\
\hline Feedbacks & Project list & $\begin{array}{l}\text { List of "Ideas in } \\
\text { Action" }\end{array}$ & Visual illustration \\
\hline Final products & Lego Products & $\begin{array}{l}\text { Starbucks product, } \\
\text { experience, or } \\
\text { involvements }\end{array}$ & $\begin{array}{l}\text { Collections of } \\
\text { manga }\end{array}$ \\
\hline
\end{tabular}

\section{Conclusion and Future Works}

In this paper, we have discussed a new method of utilizing casual data in creating user generated design. We have described how this system can be used as a collaborative tool between product/service developers and consumers. Both product/service developers and consumers can receive benefits from our proposed system.

We have succeeded in developing a working prototype in this research, thus realizing the concept of crowdsourcing described by Howe [5] into its practical use. However, the current system is still classified as prototype and requires some minor adjustments. This system is still limited to be used for analyzing 
Japanese sentences and directed to Japanese users. In the future, we would like to develop this system for international users.

Regardless of its limitations, we have described the versatility of our proposed system. We believe that the system can be applied in strategic marketing, product development, or as a promotional tool that utilizes the voice of customers.

\section{Acknowledgement}

We would like to thank Toyota Motor Co. and Dai Nippon Printing Co. Ltd. who contributed to this study by providing invaluable feedbacks and supports. Furthermore, we would like to express our gratitude to the students of Creative Contents Design Course, Kyushu Graduate School of Design who provided us the illustrations for our system.

\section{References}

[1] Dharma, A.A.G., Kumamoto, H., Kochi, S., Kudo, N., Wei, G., Chiu, S. \& Tomimatsu, K., The Utilization of Social Networking Service and Japanese Manga in User Generated Design, in Proc. of 2011 International Conference on Electrical Engineering and Informatics (ICEEI), 2011.

[2] Sayaka, A., Kato, N., Muraoka, Y. \& Yamana, H., Cross-media Impact on Twitter, in Proc. International Workshop on Search and Mining Usergenerated Contents, ACM, pp. 111-118, 2010.

[3] Serota, L. \& Rockwell, D., An Introduction to Casual Data, and How It's Changing Everything, Interactions, 17(2), pp. 43-47, 2010.

[4] Kolko, J., Abductive Thinking and Sensemaking: The Drivers of Design Synthesis, MIT Press Journals, 26(1), pp. 15-28, 2010.

[5] Howe, J., The Rise of Crowdsourcing, Wired, 14(6), 2006.

[6] Brabham, D., Crowdsourcing as a Model for Problem Solving: An Introduction and Cases, Convergence, 14(1), p. 75, 2008.

[7] Chiang, C. \& Tomimatsu, K., The Effort of Social Networking on Social Behavior - Integrating Twitter, Mobile Devices, and Wearable Clothing as an Example, Lecture Notes in Computer Science, 6763, pp. 30-37, 2011.

[8] Cuusoo.com, Cuusoo System, http://www.cuusoo.com/, (19 November 2011).

[9] Mystarbucks Idea, Starbucks Corporation, http://mystarbucksidea.force. com/, (19 November 2011).

[10] Twitter Shindanmaker, Shindanmaker.com, http://shindanmaker.com/, (19 November 2011).

[11] Twitter Developers, Twitter, http://dev.twitter.com/, (19 November 2011). 
[12] Yahoo! Japan Developer Network, Yahoo Japan Corporation, http://developer.yahoo.co.jp/, (19 November 2011).

[13] Fry, B., Visualizing Data: Exploring and Explaining Data with the Processing Environment, O'Reilly Media, 2007. 